\title{
Measurement Research on Long-term Deformation Law of Operating Metro Shield Tunnel in Soft Soil Area
}

\author{
Ming-Yu LI ${ }^{1, a,{ }^{*}}$, Li-Guang SUN ${ }^{2, b}$, Yan-Wei ZHANG ${ }^{1, c}$, Li-Bo ZHANG ${ }^{1, d}$ \\ ${ }^{1}$ Zhengzhou University, Henan Zhengzhou, 450001, China \\ ${ }^{2}$ Zhengzhou Metro co., LTD, Henan Zhengzhou, 450000, China

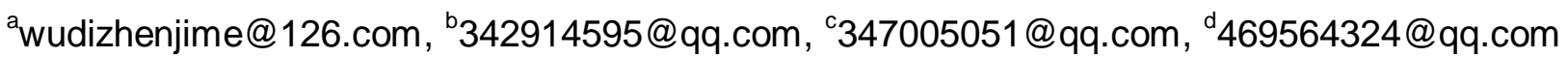 \\ ${ }^{*}$ Corresponding author
}

Keywords: Soft Soil Area, Operating Subway, Straight Joint, Shield Tunnel, Long-term Settlement Deformation.

\begin{abstract}
To operating subway shield tunnel with straight joint in soft soil area as analysis object, with statistical analysis of seven-year elevation and settlement data, and introduction of per meter elevation difference and per meter settlement difference, systematic research on the distribution and long-term law of the tunnel have been done. The study shows that, the elevation data curve characteristics is very important to judge the longitudinal deformation characteristics of operating tunnel. At the beginning of operation period, tunnel settlement is faster. With increasing time, the average monthly settlement decreases gradually. For a whole line, the average monthly settlement value of the tunnel is between- $2 \mathrm{~mm}$ and $2 \mathrm{~mm}$. The tunnel settlement is approximately linearly proportional to the formation compression deformation and groundwater level. With groundwater level rising, the average monthly settlement of operational tunnel decreases gradually, and vice versa. The longitudinal deformation curve of each tunnel is approximately Gaussian curve. The symmetric center is approximately connected aisle. After operating seven years, the per meter settlement difference value is less than $1 \mathrm{~mm}$ and the annual variation value is less than $0.15 \mathrm{~mm}$ in a whole line.
\end{abstract}

\section{Introduction}

In recent years, the long-term settlement and longitudinal settlement problem of operating subway shield tunnel is gradually concerned. The reason is that segment crack, joint leakage; joint staggering and opening, and track irregularity is caused by larger cumulative settlement and longitudinal differential settlement of operating tunnel in soft soil area.

The references [1-6] studied the measured settlement data of a specific section in the operating subway shield tunnel. The references [7, 8] researched the longitudinal curvature distribution characteristics of the operating tunnel's cumulative settlement curve. The references $[9,10]$ analyzed the problem of long-term settlement deformation caused by tunnel leakage. These references studied mainly settlement data rather than elevation data. But in fact, the elevation data reflect the longitudinal deformation characteristics of operating tunnel more than settlement data. The results of these studies couldn't represent the general rule of the long-term settlement deformation and the longitudinal deformation of the operating tunnel, because the scope of the analysis results was limited by the specific geological condition, the specific test condition and parameter, and the specific surrounding environment and so on.

When the statistical sample quantity is enough, a particular sample data has little impact on the general data rule in mathematical statistics analysis. Therefore the analytical result can reflect the rule. Therefore, to all tunnels of Shanghai metro line No.2 as analysis subject, with statistical analysis of seven-year operating elevation and settlement data, and introduction of per meter elevation difference and per meter settlement difference, systematic research about the logitudinal distribution and long-term law of operating tunnel have been done. 


\section{Tunnel Longitudinal Deformation Distribution Rule}

The first phase of Shanghai metro line No.2 is from zhongshan park station to longyang road station. The length of the whole line is 16.3 kilometers. All tunnels are mainly through the muddy silty clay, the silt clay, the sandy silt clay. The joint segment is used in all shield tunnels. Each lining ring contains a key block, two adjacent blocks, two standard blocks, and an arch bottom block. The outer diameter is $6.2 \mathrm{~m}$. The inner diameter is $5.5 \mathrm{~m}$. The ring width is $1 \mathrm{~m}$. The joint bolt is M30. The design strength grade of segment concrete is $\mathrm{C} 50$. The elastic gasket used for joint waterproofing is composed of water swelling rubber and neoprene. All tunnels of a whole line started trial operation on September 20, 1999. It has gone into service on June 11, 2000.

The seven-year elevation and settlement curve of operating tunnel is shown in figure 1 . The cumulative elevation and settlement increases year by year. Along the axis of the tunnel, there is no obvious settlement distribution, but the elevation distribution is very obvious. Approximate to the connected aisle as the center of symmetry, the elevation curve of each tunnel is Gauss distribution between two metro stations. The maximum of elevation data is $t$ near connected aisle. The inflection point of the elevation curve is near the working well. It indicates that two metro stations can constrain the longitudinal deformation of tunnel.

In addition, there are differences on the longitudinal distribution of the elevation and the settlement. The longitudinal deformation distribution of the tunnel is reflected by the elevation curve. The long-term deformation rule of the tunnel is reflected by the settlement curve. Both of them are very important for judging structural safety of the operating tunnel. Therefore, it is not reasonable for judging structural safety of the operating tunnel only on the basis of the measured settlement data in some references. And sometimes the evaluation result could be wrong.

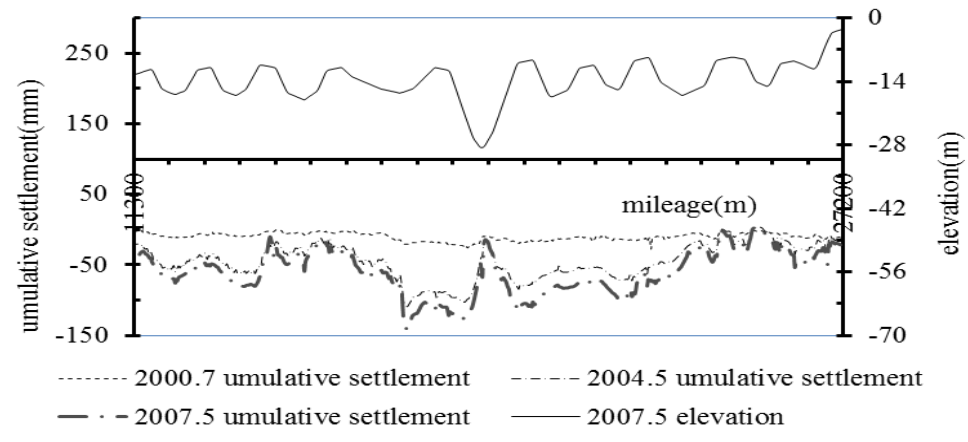

Fig. 1 Settlement and Elevation Curves of the Whole Operating-tunnel Line

\section{Tunnel long-term Settlement Rule}

The long-term and longitudinal distribution ecurves of a typical tunnel settlement is shown in figure 2 . For monitoring point S1516, the cumulative settlement increases and the average monthly settlement decreases year by year. The layered settlement and the water level were monitored near the zhongshan park metro station and the Shanghai University of political science and law.

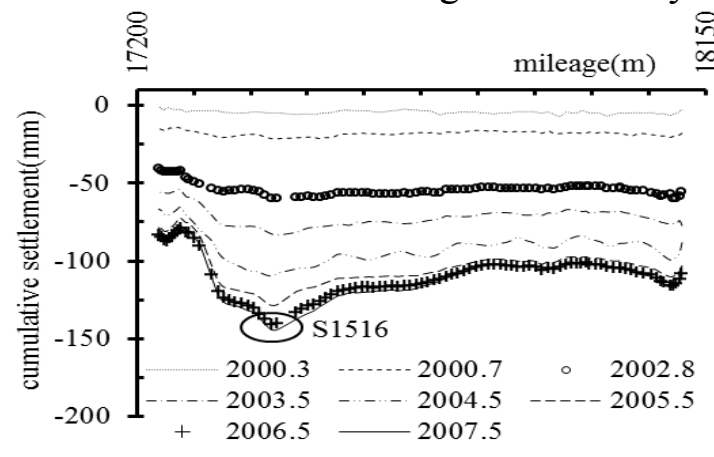

(a)

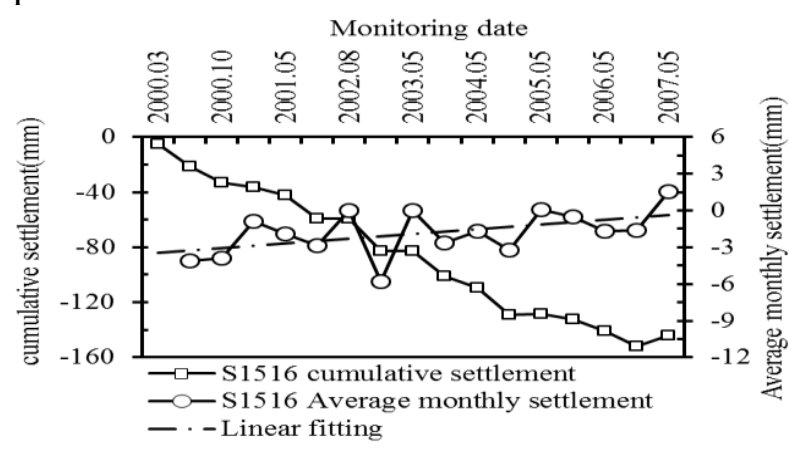

(b)

Fig. 2 Long-term Settlement Curves of a Typical Tunnel 
The monitoring data are compared with the long-term settlement data of the nearby tunnel in figure 3 . It can be seen that it is a linear proportional relationship among operating tunnel settlement, formation compression and water level. As the water level rise, the average monthly settlement of the operating tunnel and the formation compression decreases.

year

197619801984198819921996200020042008

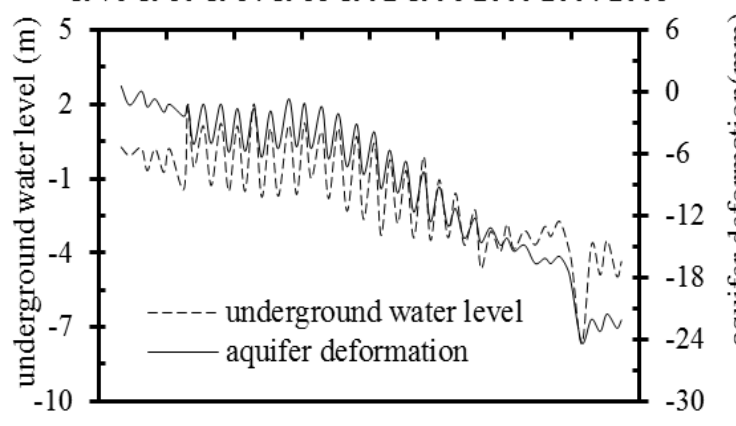

(a)Near the Shanghai University of political science and law

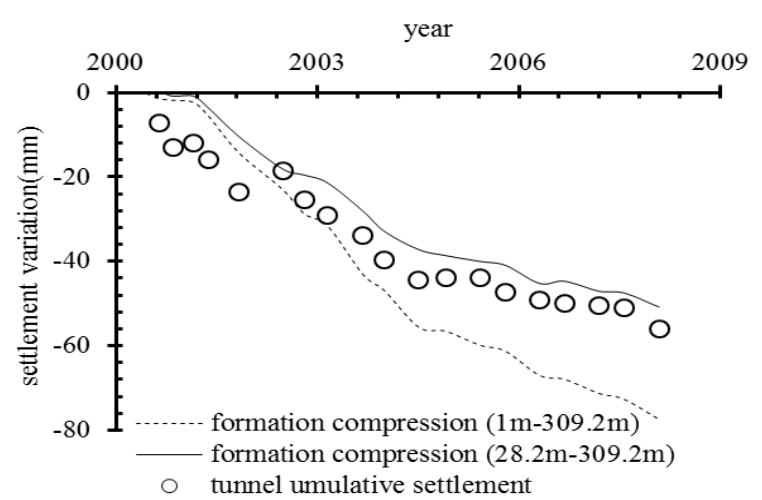

(b)Near the Zhongshan park metro station

Fig. 3 Relation Curves of Tunnel Settlement, Formation Compression and the Water

With the statistical analysis of these monitoring data, the average monthly settlement of the seven-year operating tunnel is studied in figure 4.

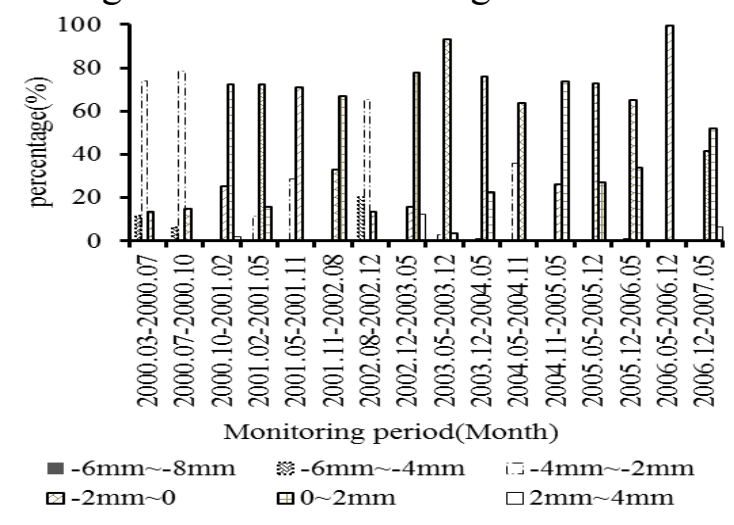

Fig. 4 Tunnel Average Monthly Settlement

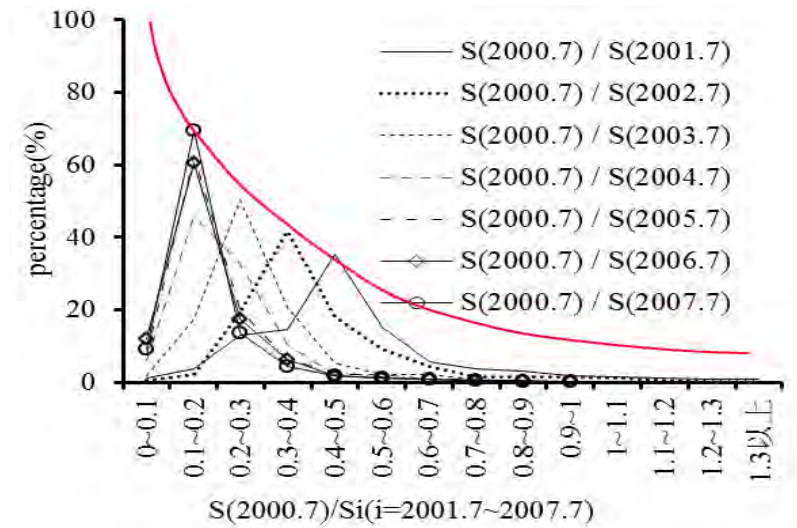

Fig. 5 Settlement Variation Ratio in the Trial Operation Stage and Formal Operation Stage of Tunnel

There are nearly 1700 tunnel settlement points in all tunnels of metro line2. The settlement of tunnel was faster in the trial operating phase. From March 2000 to July 2000, the average monthly settlement of about $75 \%$ of monitoring points is between $-4 \mathrm{~mm}$ and $-2 \mathrm{~mm}$. From July 2000 to May 2007, the average monthly settlement of all monitoring points is between $-2 \mathrm{~mm}$ and $2 \mathrm{~mm}$.

The cumulative settlement of the trail operating tunnel is compared with the yearly cumulative settlement of the operating tunnel in figure 5. The cumulative settlement ratio value of July 2000 and July 2007 is about 0.1 for about $70 \%$ of all settlement points in a whole line. With increasing time, the curve peak of statistical data moved toward the vertical axis. This means that the cumulative settlement of the operating tunnel is still increasing. And the cumulative settlement ratio of the trail operation phase and each year of the operation phase decreases gradually. And the percentage of settlement points is still on the rise under the same settlement ratio.

\section{Tunnel Longitudinal Elevation Difference}

The larger cumulative settlement and longitudinal differential settlement ofen leads to joint staggering in the operating tunnel. The per meter elevation difference can be used to estimate the cumulative value of the joint staggering. In figure 6, approximate to the monitoring point of largest cumulative elevation as the center of symmetry, the per meter elevation difference curve is the antisymmetric distribution and 
inversely proportional to the curvature of the curve. When the curvature of the curve is zero, the value remains the same.

The per meter elevation difference data of all monitoring points of May 2007 is shown in figure 7. According to reference [11], when the joint staggering value is greater than $14.5 \mathrm{~mm}$, the joint leakage of segment will be occur in the tunnel. The statistics shows that the per meter elevation difference value of $61 \%$ of all monitoring points is greater than $14.5 \mathrm{~mm}$. This suggests that the leakage check should be done for these points.

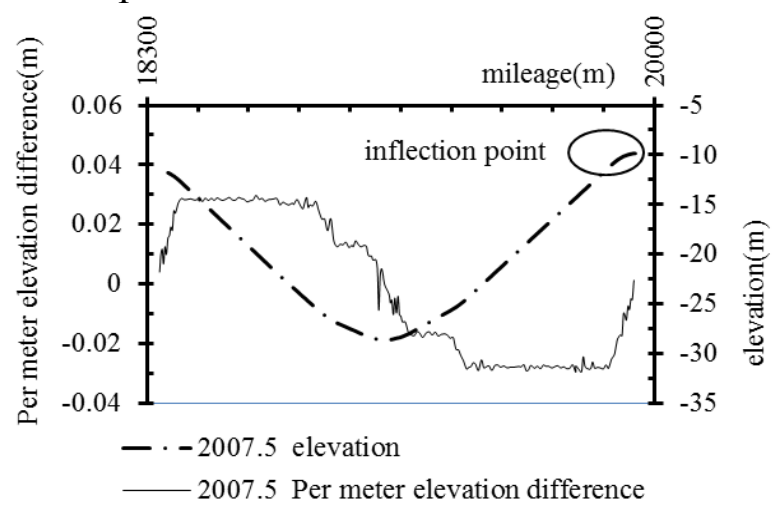

Fig. 6 Per meter Elevation Difference Distribution Curves of a Typical Tunnel

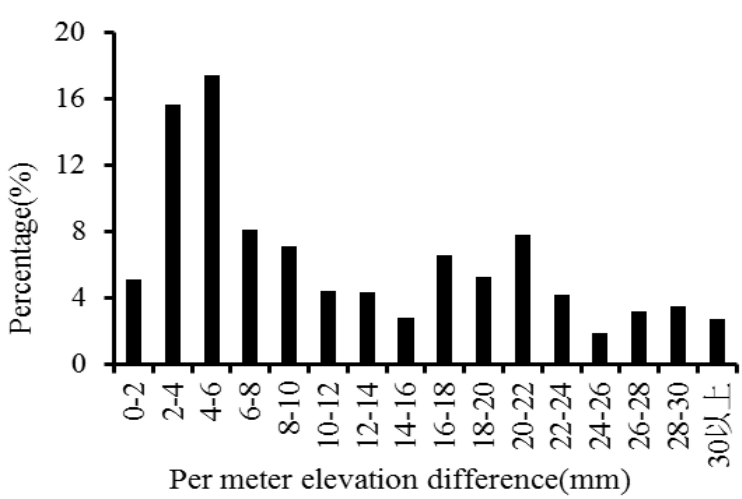

Fig. 7 Per Meter Elevation Difference Histogram of the Whole Operating-tunnel Line

\section{Tunnel Longitudinal Settlement Difference}

The per meter settlement difference can be used to estimate the change rate of the joint staggering. The per meter settlement difference curve of a typical tunnel of May 2007 is shown in figure 8. From March 2000 to May 2007, the per meter settlement difference variation is about between $-0.15 \mathrm{~mm}$ and $0.15 \mathrm{~mm}$. The per meter settlement difference variation is the biggest near the connected aisle.

The per meter settlement difference data of all monitoring points of May 2007 is shown in figure 9. After seven years, for about $96 \%$ of all monitoring points, the per meter settlement difference value is less than $1 \mathrm{~mm}$ and the annual variation value is less than $0.15 \mathrm{~mm}$ in a whole line.

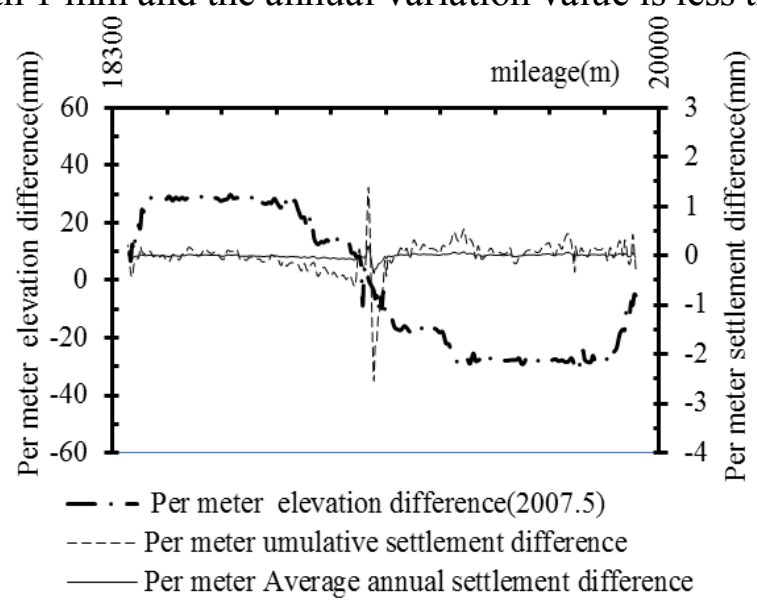

Fig. 8 Per Meter Settlement Difference Distribution Curves of a Typical Tunnel

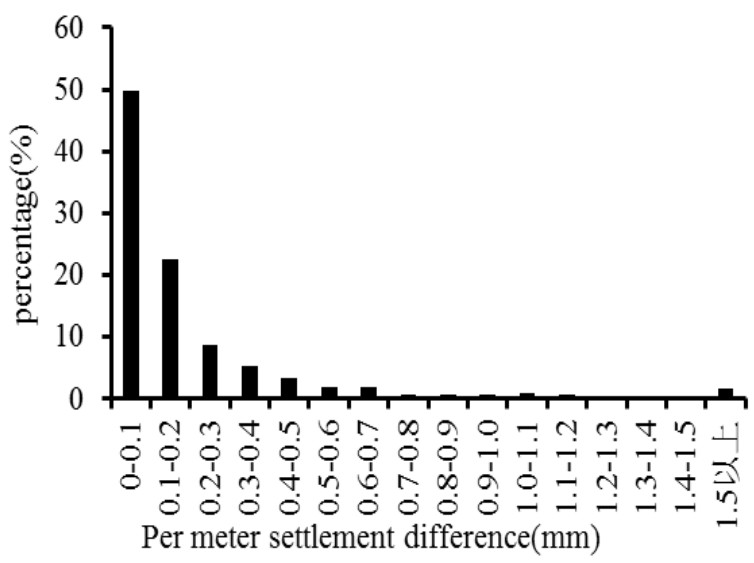

Fig. 9 Per Meter Settlement Difference Histogram of the Whole Operating-tunnel Line

\section{Conclusion}

To all operating tunnels of Shanghai metro line 2 as analysis object, the statistical analysis for seven-year elevation and settlement data is used to juge the longitudinal deformation characteristics and the long-term settlement law of the tunnel. The longitudinal distribution characteristics and change rate of the joint staggering is studied by introducing per meter elevation difference and per meter settlement difference. The main conclusions are as follows: 
There are differences on the longitudinal distribution of the elevation and the settlement. The long-term deformation rule of the tunnel is reflected by the settlement curve. Both of them are very important for judging structural safety of the operating tunnel. Both of them are very important for judging structural safety of the operating tunnel.

Approximate to the connected aisle as the center of symmetry, the elevation curve of each tunnel is Gauss distribution between two metro stations. The maximum of elevation data is $t$ near connected aisle. The inflection point of the elevation curve is near the working well. It indicates that two metro stations can constrain the longitudinal deformation of tunnel.

It is a linear proportional relationship among operating tunnel settlement, formation compression and water level. As the water level rise, the average monthly settlement of the operating tunnel and the formation compression decreases.

The settlement of tunnel was faster in the trial operating phase. From March 2000 to July 2000, the average monthly settlement of about $75 \%$ of monitoring points is between $-4 \mathrm{~mm}$ and $-2 \mathrm{~mm}$. From July 2000 to May 2007, the average monthly settlement of all monitoring points is between $-2 \mathrm{~mm}$ and $2 \mathrm{~mm}$.

After seven years, the per meter elevation difference value of $61 \%$ of all monitoring points is greater than $14.5 \mathrm{~mm}$. For about $96 \%$ of all monitoring points, the per meter settlement difference value is less than $1 \mathrm{~mm}$ and the annual variation value is less than $0.15 \mathrm{~mm}$ in a whole line.

\section{References}

[1]J.W. Chen, Deformation measuring of the metro tunnel and deformation data analysis of shanghai metro line no. 1. Shanghai Geology, Vol. 71 (2000) No.2, pp. 51-56. (In Chinese)

[2]F. Liu, Long-term settlement of metro in soft ground and its influence on safety. (MS., Nanjing University, China 2013). (In Chinese)

[3]D.W. Huang, S.L. Zhou, Q.M. Gong, K. W, Characteristic analysis of non-uniform settlement for different structures of metro in soft soil districts. Journal of Tongji University (natural science), Vol. 41 (2013) No.1, pp. 95-110. (In Chinese)

[4]Y.F. Chen, Research on the creep behavior of Shanghai soft clay and the differential settlement of shield tunnel. (Ph.D., Tongji University, China 2008). (In Chinese)

[5]R.L. Wang, J.H. Liu, Monitoring and research for the longitudinal metro under long-term operation. Underground Engineering and Tunnels, (2001) No.1, pp. 6-11. (In Chinese)

[6]L. Wang, A research of long-term longitudinal settlement \& deformation of the tunnel by soft soil shield method. China Municipal Engineering, (2013) No.5, pp. 89-91. (In Chinese)

[7]Y.D. Ye, Research on deformation and method of health diagnose of operational subway structures in soft soil. (Ph.D., Tongji University, China 2007). (In Chinese)

[8]H.W. Huang, X.L. Zang, Study on the longitudinal deformation behavior of Shield Tunnel. Underground Space, Vol. 22 (2002) No.3, pp. 244-251. (In Chinese)

[9]D.M. Zhang, Y. Liu, H.W. Huang, Leakage-induced settlement of ground and shield tunnel in soft clay. Journal of Tongji University (natural science), Vol. 41 (2013) No.8, pp. 1185-1190. (In Chinese)

[120]Y.L. Zheng, J. Pan, W.X. Han, Analysis on the settlements of metro tunnels in soft soil. Chinese Journal of Underground Space and Engineering, Vol. 1 (2005) No.1, pp. 68-74. (In Chinese)

[11]M.Y. Li, Research on Laws and Characteristics of Longitudinal Deformation and Mechanics for Metro Shield Tunnel in the Operation. (Ph.D., Tongji University, China 2011). (In Chinese) 